\title{
A Review of Overcome the Side Effect of Digestion Process on the Drugs
}

\author{
Mohammed Alwan Farhan, Abdulwahhab H. Majeed, Nuha A. Imran, \\ Wafaa Sh. Al-Zuhairi and Leqaa A. Mohammed
}

Department of Chemistry, College of Science, Diyala University, Diyala, Iraq

\begin{abstract}
This review involves the effect of digestion methods on the drugs and how to overcome the harms of digestion process by designing the suitable a polymeric drug system that has ability to hold out the harsh conditions of the acid in stomach. And it involves different type of backbone polymer to prepare new drug polymers form, this new polymer drugs included many benefits such as release the minimum amount of drug over an prolonged time by organized delivery of drug and the side effect of drugs will reduced. This process includes the modification of natural polymer such as chitosan, starch, cellulose, gelatin by carried out with a spacer, and grafted the new copolymer with amino drug such as amoxicillin (HA), and characterize it by UV Spectroscopes, (DSC) and (TGA) and physical properties was discussed. And know the ability of drug release in different $\mathrm{pH}$. In this review we concluded that the best way to overcome the side effect of digestion process on the drugs by using the medicine as polymer drugs, and the best polymer used was natural polymers, the prepared polymer drug have thermal stability more than the drug alone, this indicate extra expire date with more safety of drug satiability.
\end{abstract}

\begin{tabular}{ll} 
& \multicolumn{1}{c}{ Abbreviations } \\
FTIR & Fourier Transform Infra red \\
${ }^{1} \mathrm{H}-\mathrm{NMR}$ & Proton Nuclear Magnetic Resonance \\
$\mathrm{UV}$ & Ultra Violet \\
$\lambda_{\max }$ & Wave length at which maximum absorbance \\
& occur
\end{tabular}

Received: February 5, 2021; Accepted: April 4, 2021

Keywords and phrases: digestion, natural polymer, amino drugs, amoxicillin, drug copolymer.

Copyright (C) 2021 Mohammed Alwan Farhan et al. This is an open access article distributed under the Creative Commons Attribution License, which permits unrestricted use, distribution, and reproduction in any medium, provided the original work is properly cited. 
$\mathrm{H}$

HA

DSC

TGA

MA

AA

CAN

PAA

PVA

PAC

PAM

PEG

APS

MEC

MTC
Starch grafted maleic anhydride

Starch grafted maleic anhydride and substituted with Amoxicillin

Differential scanning calorimetric

Thermo gravimetric analysis

Maleic anhydride

Acrylic acid

Ceric ammonium nitrate

Poly acrylic acid

Poly vinyl alcohol

Poly acryloyl chloride

Poly acryl amide

Poly ethylene glycol

Ammonium per sulphate

Minimum effective concentration

Maximum toxic concentration

\section{Introduction}

Diet is one of the main requests for continue organisms to live and supply energy to the body and growing of tissues. The basic ingredients of our diet are carbohydrates, fats, protein, minerals and vitamin. The converted of mixture substances dietto simple absorbed forms is named digestion [1]. General organization system of the human digestive is shown below in Figure 1. 


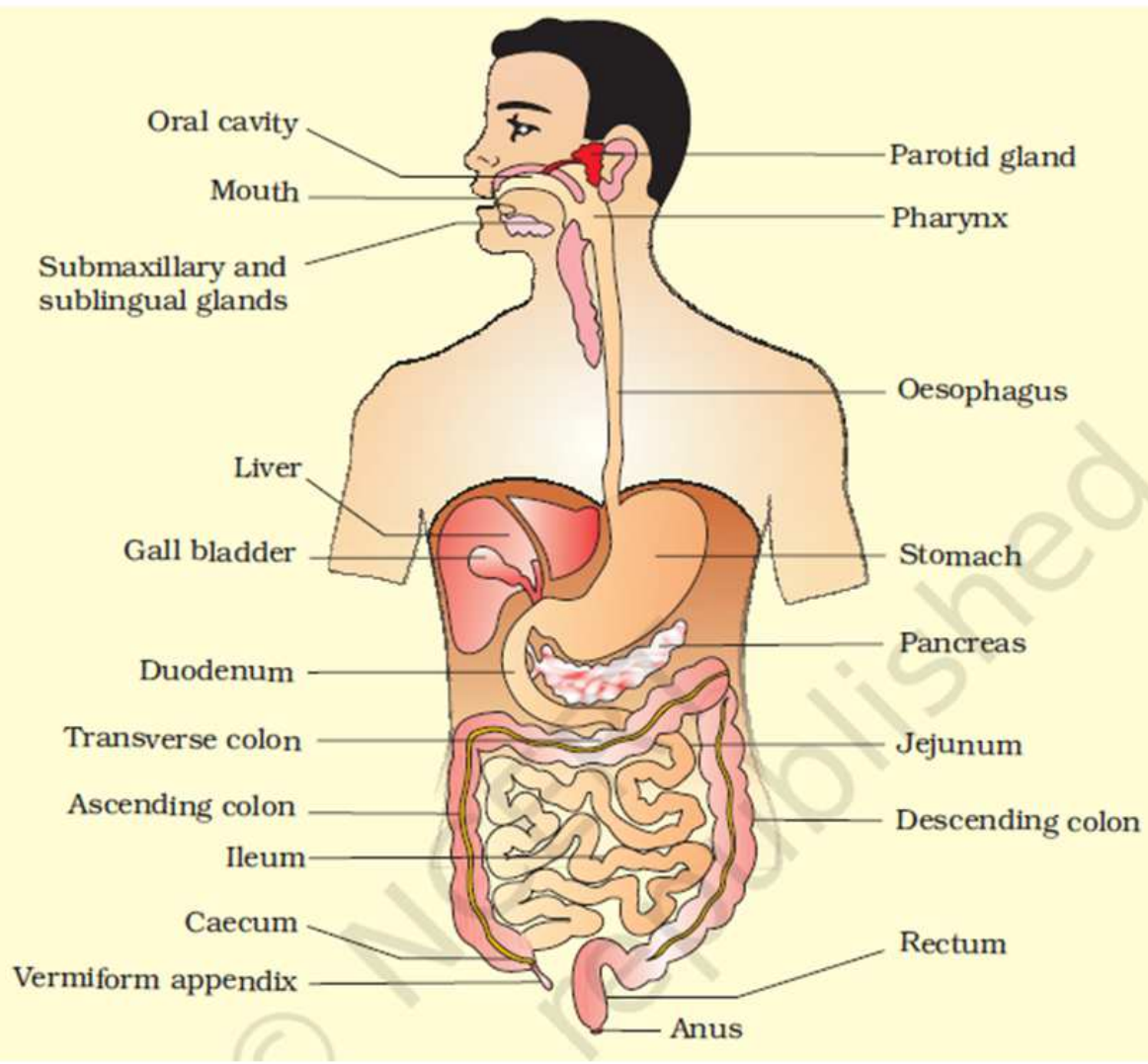

Figure 1. The human digestive system.

\section{The Influence of Drugs by Digestion Process}

The absorption is the ended process of digestion pass through the intestine to the blood [2]. Among many ways of drug delivery, the oral way is the finest, it is take as a capsule or tablet, like (Amoxicillin, Ampicillin, Salbutamol, Mefenamic acid etc.) for note the capsules are made from a gelatin to carry the drug inside it, and when it reaches the stomach, the capsule is dissolved by stomach acid within only four minutes, so it is faster to affect than tablets.

The capsules have been manufactured for many reasons, including: some drugs are sensitive to light or air, and others have un acceptable a taste or odor, Therefore, the container is not transparent and is not permeable to air but what are the effects of stomach acids or enzymes on the functional groups of these drugs, The stomach have acidic fluid [3]. It may lead to decreased the activities of these function group and that may cause 
losses of drugs action [4], [5]. Let take amoxicillin as example. Amoxicillin with molecular formula $\left(\mathrm{C}_{16} \mathrm{H}_{19} \mathrm{~N}_{3} \mathrm{O}_{5} \mathrm{~S}\right)$, it is active against (Gram + and Gram - bacteria) it is contains several effective groups like (amines, hydroxyl, carboxyl) this functional groups may be effected by acid stomach lead to decomposition and removal cause minimum the efficiency of the drugs or its solubility [6], so to end this problem it must designing drug delivery systems to release minimum drugs in the desired location [7]. It gives high benefits like improving availability of drugs, improve acceptance [8].

These methods include loading the drug on the polymer to keeps it when path from the severe location of the stomach and releases it into gastrointestinal tract. This process called control drug release [9] as shown in Figure 2.

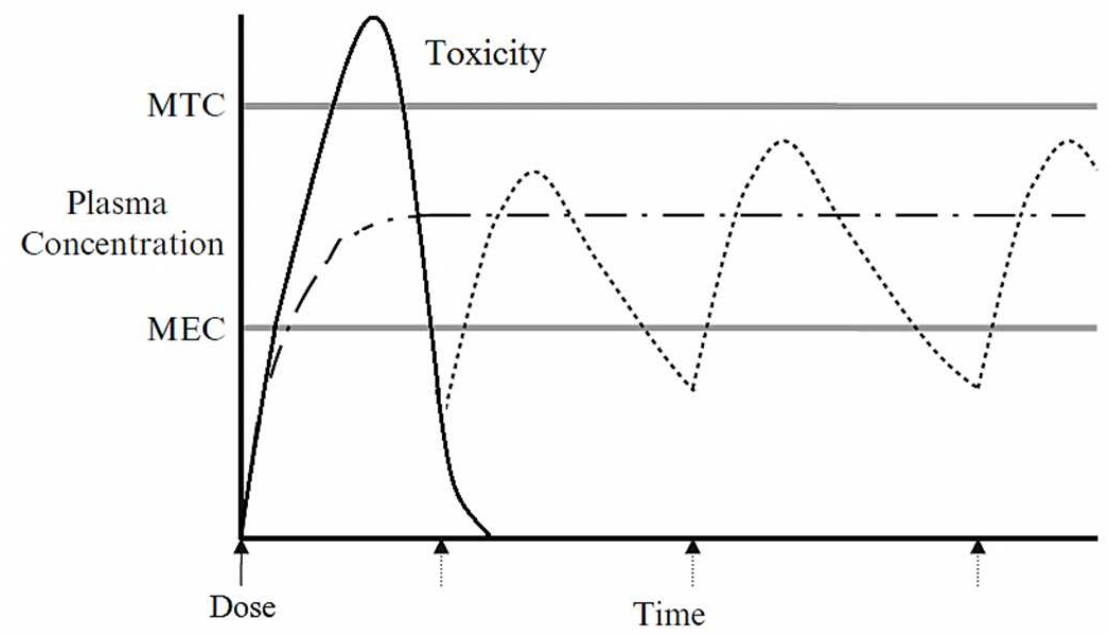

Figure 2. Concentration of drug in plasma against time of dosage to controlled release drug delivery system [9].

\section{Natural and Synthetic Polymer}

There are many sources of polymers uses in the preparation of polymer drugs, some of these synthetic polymers are (PAA, PVA, PEVA, PAC, PAM, PEG) and among the natural polymers like (starch, cellulose, glycogen, chitosan, gelatin), all of these polymers offer functions group like (-COOH, $-\mathrm{NH} 2,-\mathrm{OH},-\mathrm{COCl})$ uses to binding the drugs on the backbone of polymer [10], [11], [12] as shown in Figure 3. 


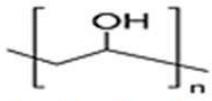

poly vinyl alcohol (PVA)

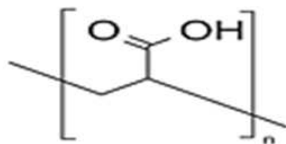

poly acrylic acid (PAA)<smiles>CCOCC1CO1</smiles>

poly ethylene glycol (PEG)

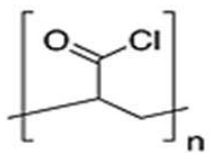

Poly acryloyl chloride (PAC)

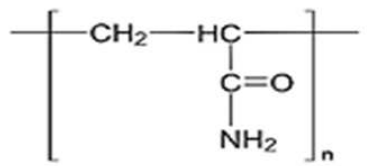

poly acryl amide (PAM)

Figure 3. Functional groups of synthetic polymers [10], [11].

Natural polymers such as starch and their derivatives refer to a group of polymers widely used in the biomedical and pharmaceutical fields for controlled release application. Several polysaccharides such as starch, cellulose and chitosan have been used extensively either alone or in combination with their modified form to regulate drug release from many drug delivery systems [13], [14]. It has been found that the best types of polymers used in the preparation of polymer drugs is the natural polymers, such as polysaccharide (starch, cellulose, chitosan). Because they are nontoxic, more biodegradable, less expensive, and freely available, compared to their synthetic polymers [13], [14], [15].

\section{Prodrug Polymers}

in the 1950s, the first term introduced was "prodrug" to denote chemical inactive derivatives that can be used to temporarily alter the physical and chemical properties of drugs, to extend their potency and effectiveness or to reduce their toxicity. the polymer separator can be considered as a drug delivery method that shows its therapeutic efficacy by releasing less therapeutic drug molecules from the polymer backbone for a long period which increases the drug's usefulness by increasing the duration, bioavailability, for as long as possible [16], [17]. 


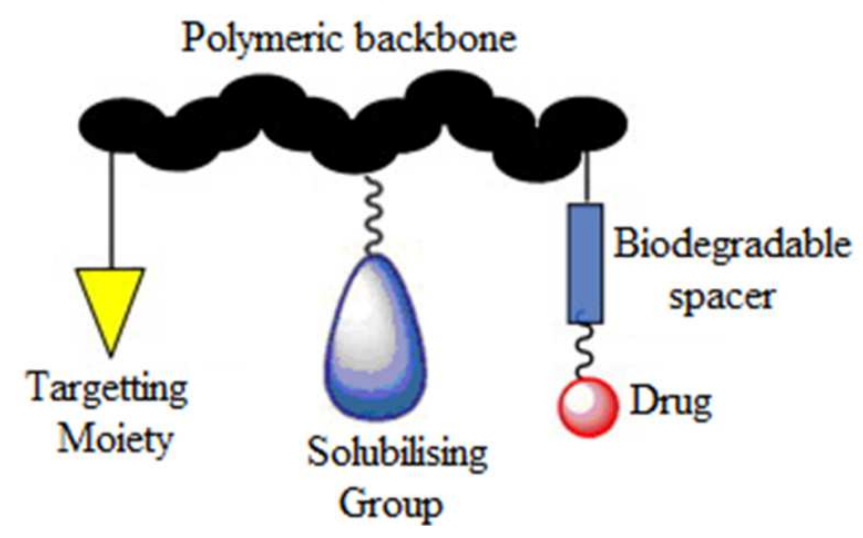

Figure 4. Structure of prodrug polymer [16], [17].

The main advantages of degradable polymers are that the result of hydrolysis is not toxic or completely eliminated from the body by natural metabolic pathways, with minimal side effects [18].

\section{Advantage of Prodrugs Polymers [16], [17], [19]}

A- Increased the solubility of drugs in water, improvement the accessibility of drug:The very slight solubility of some drugs cases a problem for control. Increasing the solubility of drug can be changed by conjugate it with the polymer backbone such as starch to make polymer drugs.

B- Protection or safety of drug from degradation by a wide range of enzymatic activities before its arrive to desired site, and stay its activity during circulation, transport to targeted organ.

C- The major benefit of prodrug polymers is their capability to offer second or third order affecting, by means its capability to release a drug at specific sites tissue.

D- Extension of drug action:- Prodrugs has a high renal threshold because its molecular weight very high, so the conjugated of drug-polymer will not pass from circulation, and half-life of the drug in the blood circulation will increase.

\section{Controlled Drug Release [6], [20]}

Release of drug from (HA) was studied in vitro, $(100 \mathrm{mg})$ of polymer drug added immediately in $(50 \mathrm{ml})$ buffer solution at room temperature. The $\lambda_{\max }$ was measured at different time and different $\mathrm{pH}$ values (1.5-7.5) by using UV spectrometer. The samples 
were analyzed by UV-spectroscopes frequent and measure repeated for five days, it was shown that the persistent release by the mole fraction measuring were created from UV. Shown the degree or speed of hydrolysis in basic medium is higher than acidic medium. Mechanism of hydrolysis polymer drug were explained as shown in the scheme below.

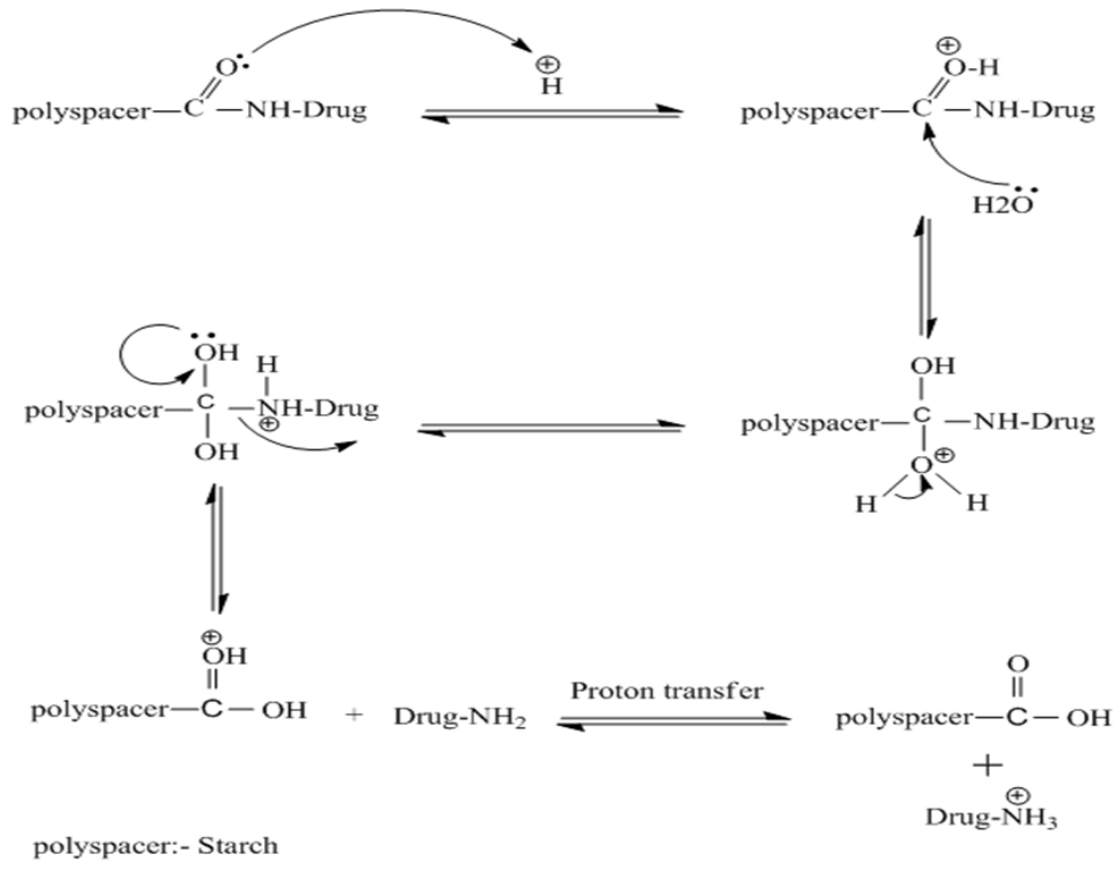

Scheme 1. Hydrolysis mechanism of polymer drug in acidic medium.

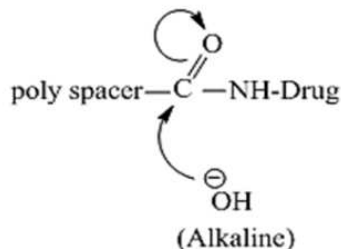

\section{Nucleuphilic addition}
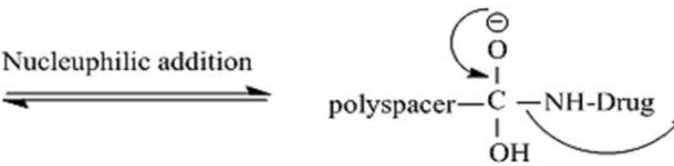

loss NH-Drug

(Alkaline)
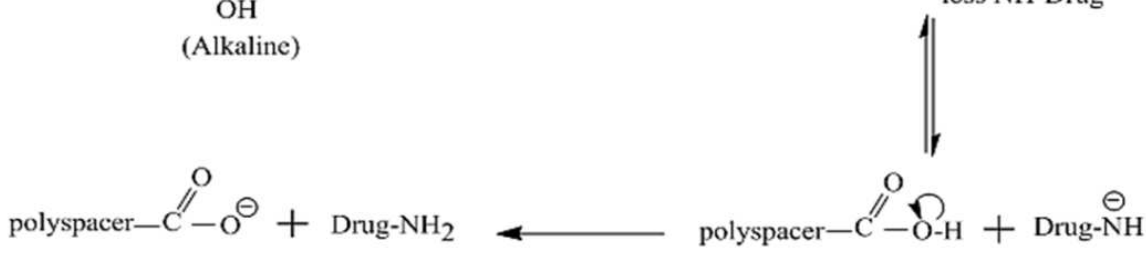

poly spacer $=$ Starch + Maleic anhydride

Drug NH2 $=$ Amoxicilline

Scheme 2. Hydrolysis mechanism of polymer drug in basic medium. 


\section{Experimental}

There are many ways to prepare polymer drugs as graft copolymers. Some of the best these methods are listed in Table 1.

Table 1. Methods of prepare polymer drugs.

\begin{tabular}{|c|c|c|}
\hline Author and Date & Title of Paper & Page \\
\hline Sana 2016 [18] & $\begin{array}{c}\text { Athesis "Synthesis and Characterization } \\
\text { of Some New Drug Derivatives of } \\
\text { Natural Polymers" }\end{array}$ & 58 \\
\hline Mohamed et al. 2017 [20] & $\begin{array}{c}\text { Synthesis and characterization of } \\
\text { cellulose grafted maleic anhydride and } \\
\text { substituted it with amoxicillin }\end{array}$ & 85 \\
\hline Prasanna et al. 2018 [6] & $\begin{array}{c}\text { Sustained release of amoxicillin from } \\
\text { hydroxyapatite nanocomposite for bone } \\
\text { infections, Progress in Biomaterials }\end{array}$ & 290 \\
\hline
\end{tabular}

\section{Result and Discussion}

For the previous methods, ceric ammonium nitrate (CAN) or ammonium per sulphate (APS) is used as initiator in the joining of vinyl monomers onto poly scurried like starch or cellulose. New polymer drug was prepared by the reaction of maleic anhydride with starch and conjugated it with amoxicillin in scheme below. 


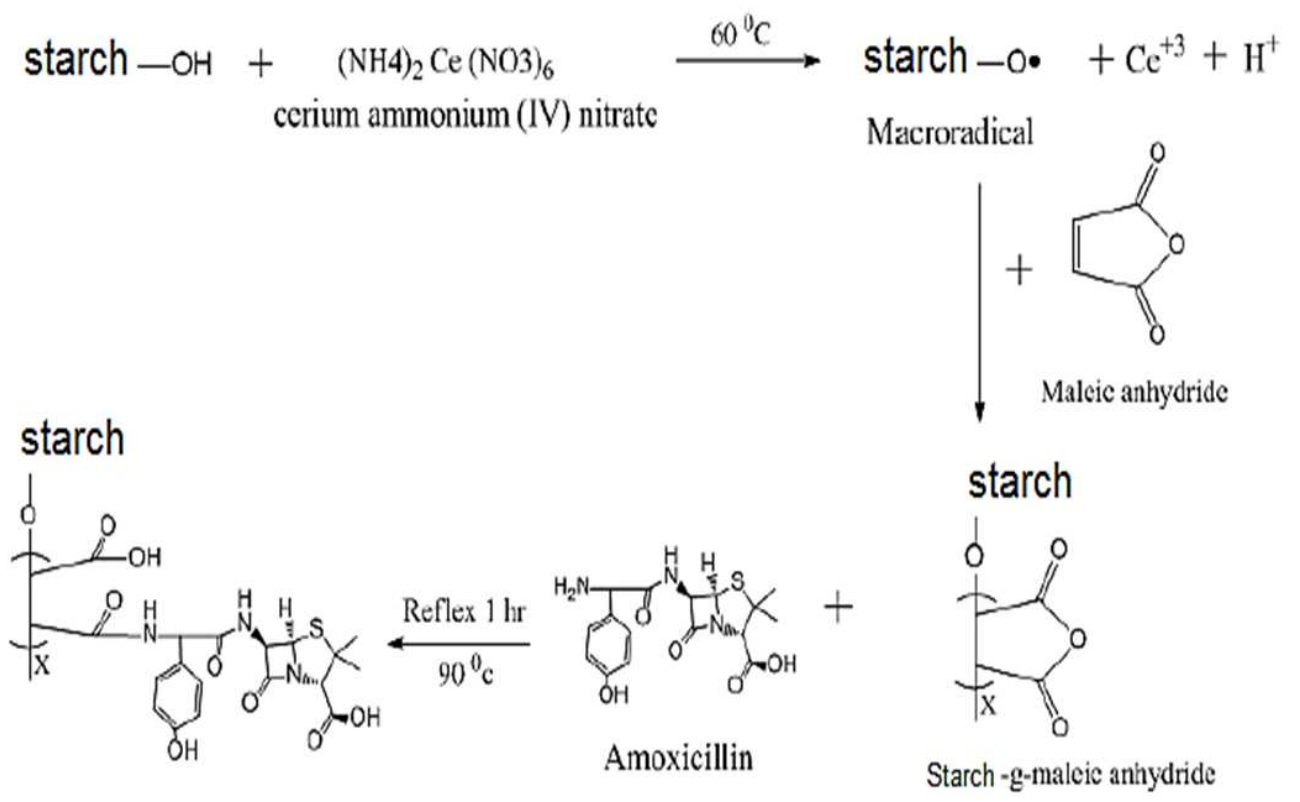

Scheme 3. Starch-g-maleic anhydride and Substituted it with amoxicillin [20].

Numerous thermal stability parameters were determined from TGA and DSC curves (Figures 5-7) as shown in Table 2 and Table 3 [21], [22].

Table 2. TGA analysis of polymer drug [21], [22].

\begin{tabular}{|c|c|c|}
\hline No. drug polymer & Temperature & Losses weight $\%$ \\
\hline H & $123,318,404$, & $3,58,38$ \\
\hline HA & 458,498, & 66,6 \\
\hline
\end{tabular}

Table 3. DSC analysis of polymer drug [21], [22].

\begin{tabular}{|c|c|c|c|c|}
\hline $\begin{array}{c}\text { No. drug } \\
\text { Polymer }\end{array}$ & $\begin{array}{c}\text { Onset } \\
\text { Temp. }{ }^{0} \mathrm{C}\end{array}$ & $\begin{array}{c}\text { End set } \\
\text { Temp. }{ }^{0} \mathrm{C}\end{array}$ & $\begin{array}{c}\text { Peak } \\
\text { Temp. }{ }^{0} \mathrm{C}\end{array}$ & $\begin{array}{c}\Delta \mathrm{H} \\
\mathbf{J} / \mathbf{g}\end{array}$ \\
\hline $\mathrm{H}$ & 51.5 & 111.1 & 59.7 & 46.61 \\
\hline $\mathrm{HA}$ & 118.6 & 146.3 & 121.3 & 43.61 \\
\hline
\end{tabular}




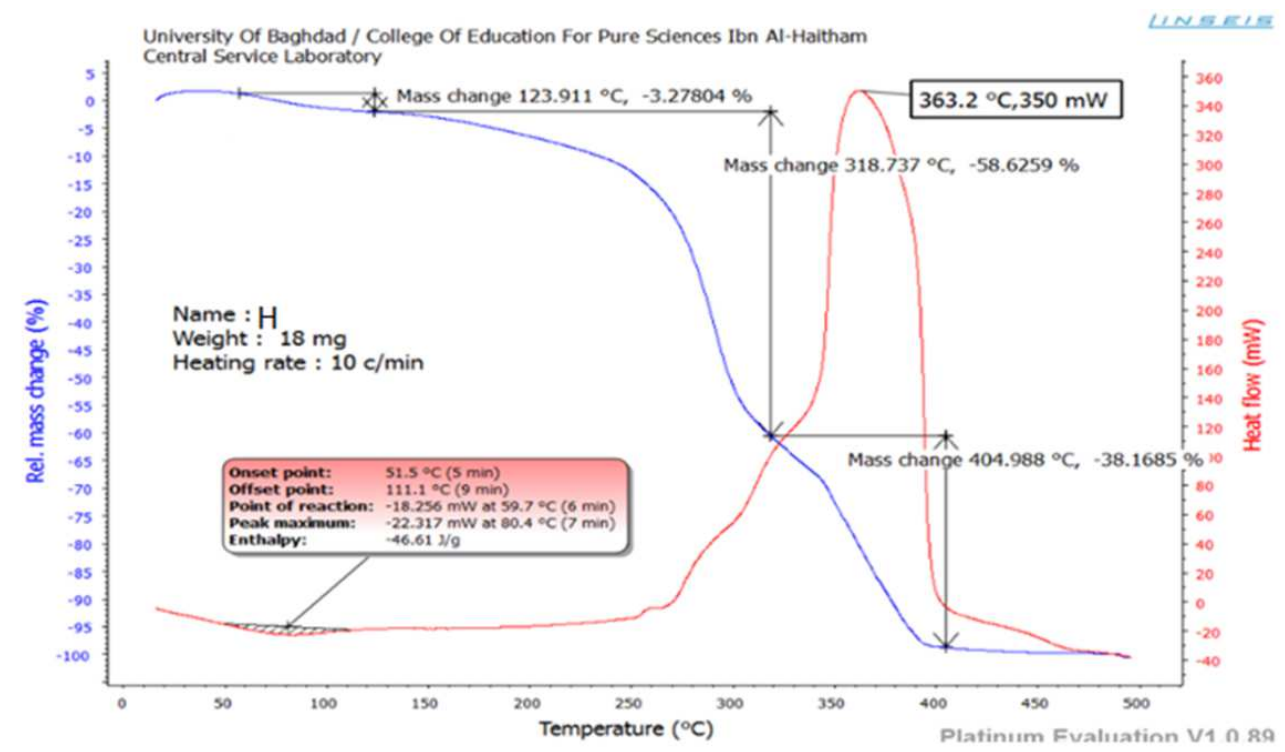

Figure 5. DSC and TGA analysis of $\mathrm{H}$.

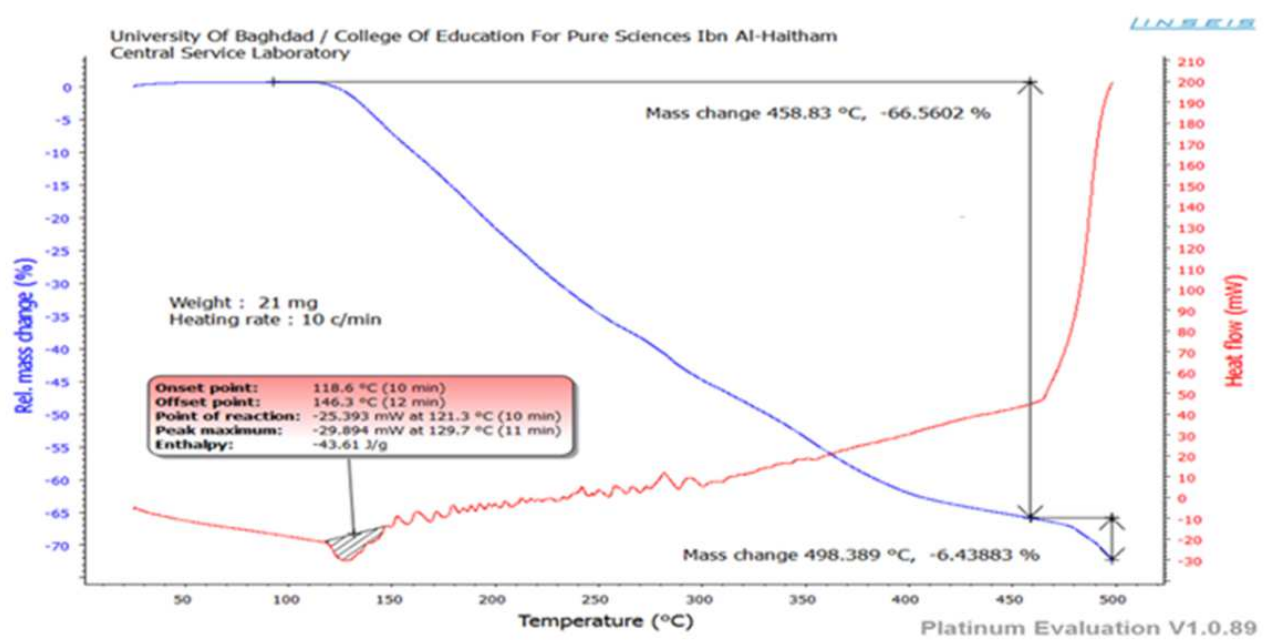

Figure 6. DSC and TGA analysis of HA. 


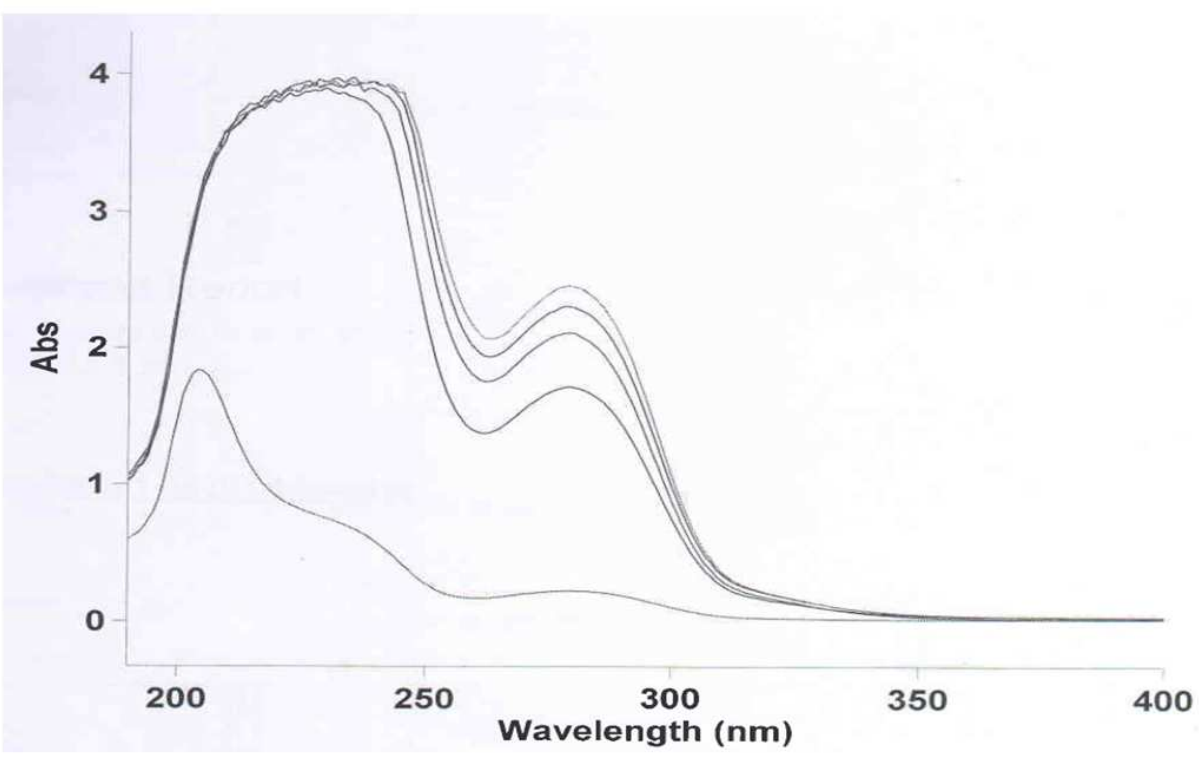

Figure 7. UV spectrum hydrolysis of polymer HA in pH7.4.

\section{Conclusion}

The digestive processes and the resulting problems in the digestive system, especially for patients with colon diseases and stomach ulcers, are very common. In addition to the effect of the drug by the acidic media of the stomach, it was necessary to find a new way to get rid of this problems. In this review we concluded that the best way to overcome the side effect of digestion process on the drugs by using the medicine as polymer drugs, and the best polymer used is the natural polymer, thermal stability of prepared polymer drug was more than the drug alone, this leads to extra expire date and provides more safety for the satiability of drug prepared, and from in vitro studied, it was looked the minimum amount release of drug by mole fraction measuring were detected by UV-visible spectroscopy indicated the rate of hydrolysis in acidic medium is less than basic medium and it is a good designing of a polymeric drug system to save the drug from the severe environments of the acid in stomach. For future researches, there are several suggestions including the planning to prepare another polymer drugs by use newfangled spacers to link the polymer with drug, and uses another drugs for a extended time, increase its affective and decrease of side. 


\section{References}

[1] F. Lahnsteiner, Digestive enzyme system of larvae of different freshwater teleosts and its differentiation during the initial phase of exogenous feeding, Czech J. Anim. Sci. 62(10) (2017), 403-416. https://doi.org/10.17221/25/2016-CJAS

[2] F. Kong and R.P. Singh, Disintegration of solid foods in human stomach, J. Food Sci. 73(5) (2008), 67-80. https://doi.org/10.1111/j.1750-3841.2008.00766.x

[3] Y. Kinoshita, N. Ishimura and S. Ishihara, Advantages and disadvantages of long-term proton pump inhibitor use, J. Neurogastroenterol. Motil. 24(2) (2018), 182-196. https://doi.org/10.5056/jnm18001

[4] L. Rodríguez-Viera et al., Carbohydrates digestion and metabolism in the spiny lobster (Panulirus argus): biochemical indication for limited carbohydrate utilization, PeerJ 5 (2017), e3975. https://doi.org/10.7717/peerj.3975

[5] B. Homayun, X. Lin and H.J. Choi, Challenges and recent progress in oral drug delivery systems for biopharmaceuticals, Pharmaceutics 11(3) (2019).

https://doi.org/10.3390/pharmaceutics11030129

[6] A.P.S. Prasanna and G.D. Venkatasubbu, Sustained release of amoxicillin from hydroxyapatite nanocomposite for bone infections, Prog. Biomater. 7(4) (2018), 289-296. https://doi.org/10.1007/s40204-018-0103-4

[7] J. Lehár et al., Synergistic drug combinations tend to improve therapeutically relevant selectivity, Nat. Biotechnol. 27(7) (2009), 659-666. https://doi.org/10.1038/nbt.1549

[8] Y. Zhang, H.F. Chan and K.W. Leong, Advanced materials and processing for drug delivery: The past and the future, Adv. Drug Deliv. Rev. 65(1) (2013), 104-120. https://doi.org/10.1016/j.addr.2012.10.003

[9] J. Siepmann, R.A. Siegel and M.J. Rathbone, Fundamentals and applications of controlled release drug delivery, Fundam. Appl. Control. Release Drug Deliv. (2012), 1594. https://doi.org/10.1007/978-1-4614-0881-9

[10] S.H. Samaha, D.M. Essa, E.M. Osman and S.F. Ibrahim, Synthesis and characterization of hydroxyethyl cellulose grafted copolymers and its application for removal of nickel ions from aqueous solutions, Int. J. Eng. Innov. Res. 4(4) (2015), 645-653.

[11] O. Olatunji, Natural Polymers Industry Techniques and Applications, Springer International Publishing Switzerland, 2016. https://doi.org/10.1007/978-3-319-26414-1

[12] P.F. Builders and M.I. Arhewoh, Pharmaceutical applications of native starch in conventional drug delivery, Starch/Staerke 68(9-10) (2016), 864-873.

https://doi.org/10.1002/star.201500337 
[13] S. Mishra, G. Usha Rani and G. Sen, Microwave initiated synthesis and application of polyacrylic acid grafted carboxymethyl cellulose, Carbohydr. Polym. 87(3) (2012), 22552262. https://doi.org/10.1016/j.carbpol.2011.10.057

[14] H.I. Meléndez-Ortiz, G.H.C. Varca, A.B. Lugão and E. Bucio, Smart polymers and coatings obtained by ionizing radiation: synthesis and biomedical applications, Open J. Polym. Chem. 5(3) (2015), 17-33. https://doi.org/10.4236/ojpchem.2015.53003

[15] M. Silva, F.N. Ferreira, N.M. Alves and M.C. Paiva, Biodegradable polymer nanocomposites for ligament/tendon tissue engineering, J. Nanobiotechnol. 18(1) (2020), 23. https://doi.org/10.1186/s12951-019-0556-1

[16] J. Nicolas, Drug-initiated synthesis of polymer prodrugs: combining simplicity and efficacy in drug delivery, Chem. Mater. 28(6) (2016), 1591-1606. https://doi.org/10.1021/acs.chemmater.5b04281

[17] E. Guégain, J. Tran, Q. Deguettes and J. Nicolas, Degradable polymer prodrugs with adjustable activity from drug-initiated radical ring-opening copolymerization, Chem. Sci. 9(43) (2018), 8291-8306. https://doi.org/10.1039/C8SC02256A

[18] Sana H. Awad, A thesis, 'Synthesis and Characterization of Some New Drug Derivatives of Natural Polymers', PhD, University of Baghdad, Iraq, 2016.

[19] J.P. Patil and H.S. Mahajan, A review on polymer drug conjugate - What, Why and How?, Int. J. Pharm. Sci. Res. 6(11) (2015), 4611-4621.

[20] Mohammed A. Farhan, Hiba B. Dheyab and Assmaa A. Hasan, Synthesis and characterization of cellulose grafted maleic anhydride and substituted it with amoxicillin, Eur. J. Pharm. Med. Res. 4(12) (2017), 84-90.

[21] M. Worzakowska, The preparation, physicochemical and thermal properties of the high moisture, solvent and chemical resistant starch-g-poly(geranyl methacrylate) copolymers, J. Therm. Anal. Calorim. 140(1) (2020), 189-198. https://doi.org/10.1007/s10973-019-08801-9

[22] M. Worzakowska, Thermal studies on the starch-g-copolymers prepared from two terpene acrylate monomers under oxidative conditions, J. Therm. Anal. Calorim. 137(5) (2019), 1559-1565. https://doi.org/10.1007/s10973-019-08036-8 